Психология. Журнал Высшей школы экономики,

2017. T. 14. № 4. C. 657-678. DOI: 10.17323/1813-8918-2017-4-657-678

\title{
РОССИЙСКИЕ АВТОРЫ В ВЕДУЩИХ МЕЖДУНАРОДНЫХ ПСИХОЛОГИЧЕСКИХ ЖУРНАЛАХ: БИБЛИОМЕТРИЧЕСКИЙ АНАЛИЗ
}

\section{А.В. ЛОВАКОВ}

${ }^{\alpha}$ Национальный исследовательский университет «Высшая икола экономики», 101000, Россия, Москва, ул. Мяснищкая, д. 20

\section{Резюме}

В статье проводится библиометрический анализ российских статей, опубликованных в ведущих международных психологических журналах (с наибольшим значением импактфактора) с 2000 по 2015 г. Выборка составила 482 статьи российских авторов. Результаты анализа показали, что в последние несколько лет наблюдается рост количества российских публикаций в ведущих международных психологических журналах. Однако темп этого роста в России ниже по сравнению с другими странами, имеющими сходные элементы академической системы. Заметное место среди российских публикаций последних лет занимают публикации сотрудников лабораторий, созданных в рамках программы «мегагрантов» (почти каждая пятая статья в 2015 г.). Естественно-научный сегмент российской психологической науки и смежных областей лучше представлен в ведущих международных психологических журналах по сравнению с социальным и прикладным сегментами. По этой же тематической области в последние годы наблюдается больший рост количества публикаций. Многие авторы, имеющие наибольшее количество статей в ведущих международных психологических журналах, являются иностранцами либо имеют второе место работы в зарубежной организации. Среди авторов крайне мало систематически публикующих статьи в ведущих журналах из года в год. Лишь шестеро авторов систематически публиковали статьи в ведущих журналах на протяжении периода с 2008 по 2015 г. Однако в последние пять лет наблюдается рост российских авторов (до 29 человек), систематически публикующих статьи в ведущих журналах.

Ключевые слова: ведуцие журналы, библиометрический анализ, российское академическое сообщество.

Индивидуальная продуктивность работников не имеет нормального распределения. Исследования на разнообразных выборках показали, что распределение индивидуальной продуктивности лучше описывается

Статья подготовлена в ходе работы в рамках Программы фундаментальных исследований Национального исследовательского университета «Высшая школа экономики» (НИУ ВШЭ) и с использованием средств субсидии в рамках государственной поддержки ведущих университетов Российской Федерации «5-100». 
с помощью степенно́го закона, или распределения Парето (O'Boyle Jr., Aguinis, 2012), которое иногда называют принципом 80/20 (например, $80 \%$ богатства владеют $20 \%$ населения). Распределение индивидуальной продуктивности ученых также характеризуется сильной левосторонней асимметрией (Lotka, 1926; O'Boyle Jr., Aguinis, 2012; Podsakoff et al., 2008; Ruiz-Castillo, Costas, 2014). Другими словами, продуктивностью выше среднего обладает меньшая часть, а продуктивностью ниже среднего - бо́льшая часть ученых. По данным международного исследования, включающего 11 европейских стран, 10\% наиболее продуктивных исследователей производят около $50 \%$ всех публикаций в этих странах (Kwiek, 2016). При этом асимметрия распределения продуктивности проявляется не только на уровне количества статей, но и на уровне количества цитирований (Podsakoff et al., 2008; Ruiz-Castillo, Costas, 2014). В связи с усиливающейся конкуренцией в академии, а также со стремлением российских университетов занимать достойное место в международных рейтингах высокопродуктивные исследователи становятся особенно важны для университетов, так как они вносят значительный вклад в продуктивность университета в целом. Целью данного исследования является анализ группы наиболее продуктивных российских исследователей, работающих в области психологической науки и в смежных областях, публикующих статьи в ведущих международных журналах.

Несмотря на большое количество научных журналов в мире, новые идеи, обеспечивающие реальный прогресс в науке, фиксируются лишь в части публикаций, выпускаемых, как правило, ведущими научными изданиями. Таким образом, наиболее значимые публикации с большей вероятностью можно найти именно в ведущих международных журналах. В целях рефлексии уровня интегрированности российского психологического сообщества в международное сообщество важно оценить представленность российских авторов в ведущих международных журналах, понять, кто эти авторы, в каких журналах и о чем они пишут и какие публикационные стратегии при этом используют. Для этого был проведен библиометрический анализ российских авторов и их статей, опубликованных в ведуших международных психологических журналах.

\section{Данные и методология исследования}

Одним из способов оценки важности, влиятельности и качества научного журнала является подсчет цитируемости его статей. На сегодняшний день существует ряд методов анализа цитирования (Mingers, Leydesdorff, 2015; Писляков, 2007), среди которых базовым и наиболее часто используемым является импакт-фактор, характеризующий среднее количество ссылок, полученных в отчетном году статьями журнала, опубликованными в течение двух предыдущих лет (Писляков, 2014). В данном исследовании под ведущими международными психологическими журналами понимались журналы, индексируемые в реферативной базе Web of Science (Science Citation Index Expanded и Social 
Sciences Citation Index) и относящиеся к первому и второму квартилям журналов с наибольшим импакт-фактором хотя бы в одной из следующих категорий: Psychology; Psychology, applied; Psychology, biological; Psychology, clinical; Psychology, developmental; Psychology, educational; Psychology, experimental; Psychology, mathematical; Psychology, multidisciplinary; Psychology, social. Принадлежность к квартилям определялась по данным базы Journal Citation Reports (Science Citation Index Expanded и Social Sciences Citation Index) за 2015 г. Данным критериям соответствуют 295 журналов.

Поиск российских статей в ведущих международных психологических журналах производился в базе Web of Science за период с 2000 по 2015 г. Статья считалась российской, если хотя бы у одного из авторов была указана хотя бы одна из аффилиаций с российской организацией. В анализе учитывались только полноценные статьи и обзоры («Article» и «Review»)

Для каждой статьи были определены или закодированы на основе содержательного анализа ряд переменных, иллюстрирующих разные ситуации, в рамках которых российские ученые могут опубликовать статью в ведущем международном психологическом журнале:

- Количество авторов.

- Статья написана только российскими авторами.

- Статья посвящена какой-либо российской проблематике.

- Статья описывает кросс-культурное исследование, в котором
Россия является одной из анализируемых стран. Обычно в таких исследованиях либо изучаются различия между культурами, либо, наоборот, проверяется инвариантность результатов в разных культурных контексTax.

- Статья написана коллективом сотрудников лабораторий, созданных в рамках программы «мегагрантов» в соответствии с Постановлением № 220 Правительства РФ ${ }^{1}$, целью которого является привлечение ученых с мировым именем, в том числе проживающих за рубежом, в российские вузы для создания научных лабораторий, способных конкурировать с ведущими лабораториями мира. На сегодняшний день в рамках этой программы создано как минимум три такие лаборатории, которые потенциально могли опубликовать статьи в психологических журналах: лаборатория междисциплинарных исследований раннего детства (ведущий ученый - Елена Григоренко), лаборатория сравнительных социальных исследований (ведущий ученый - Рональд Инглхарт), лаборатория когнитивных исследований и психогенетики (ведущий ученый Юлия Ковас). К этой категории относились не только статьи, в которых приводилась ссылка на конкретный «мегагрант», но и те статьи, где иностранные сотрудники данных лабораторий указывали аффилиацию с российским вузом, на базе которого создана лаборатория.

Из всей совокупности авторов анализируемых статей были выделены только российские авторы, т.е. авторы, у которых хотя бы в одной

\footnotetext{
${ }^{1}$ URL: http://www.p220.ru/
} 
статье хотя бы одна из аффилиаций была с российской организацией. Для каждого российского автора по выборке анализируемых статей были рассчитаны значения ряда показателей, используемых для характеристики индивидуальной продуктивности, взаимодействия с коллегами и интернационализации (Abramo et al., 2011; Hu et al., 2014):

- Р - общее количество статей;

- СОРР - среднее количество авторов на статью;

- COPS - обшее количество соавторов в анализируемом временно́м промежутке;

- ICA - общее количество стран, с которыми аффилированы авторы статей данного исследователя.

\section{Результаты}

В соответствии с описанными критериями были идентифицированы 486 публикаций. Детальный анализ показал, что четыре из них ошибочно приписаны России, т.е. среди авторов этих статей нет ни одного автора, имеющего аффилиацию с российской организацией, однако в процессе индексации этих статей базой Web of Science некоторым авторам была ошибочно обозначена другая страна (Россия вместо США). Данные статьи были удалены. Таким образом, итоговая выборка включала 482 статьи. Анализируемые статьи опубликованы в 133 журналах. Однако половина всех статей (50.1\%) опубликована в 16, а 10 и более статей - лишь в 9 журналах:
International Joumal of Psychophysiology, Physiology \& B Behavior, Personality and Individual Differences, Journal of Cross-Cultural Psychology, AIDS Care. Psychological and Sociomedical Aspects of AIDS $/ H I V$, Behavior Genetics, Intelligence, Learning and Individual Differences, Frontiers in Psychology. В таблице 1 приведен список ведущих международных психологических журналов, в которых российскими авторами опубликовано пять и более статей.

Анализ распределения статей по годам показал, что в период с 2000 по 2011 г. количество статей держится примерно на одном и том же уровне (в среднем 21 статья), а в последующие годы наблюдается линейный рост (см. рисунок 1А). В 2015 г. российские авторы опубликовали в ведущих мировых психологических журналах 84 статьи, что составляет $17.4 \%$ от общего числа таких публикаций за весь анализируемый период. Оценить это количество в абсолютных числах трудно, поэтому по тем же критериям был проведен поиск статей авторов из других стран. Для сопоставления были выбраны Польша, Чехия и Эстония как неанглоязычные страны бывшего социалистического лагеря, Бразилия (относящаяся к группе стран БРИКС ${ }^{2}$ ), а также Турция и Иран как страны, стремящиеся к более активной интеграции в международное сообщество ${ }^{3}$. Во всех анализируемых странах наблюдается рост числа публикаций, особенно ускорившийся после 2010-2012 гг.

\footnotetext{
${ }^{2}$ BRICS - сокрашение от Brazil, Russia, India, China, South Africa.

${ }^{3}$ URL: http://www.psychologicalscience.org/observer/psychology-in-iran; https:/www.elsevier.com/connect/turkeys-scientific-research-output-is-booming-but-what-about-the-quality
} 
Таблица 1

Список ведущих международных психологических журналов, в которых российскими авторами опубликовано пять и более статей

\begin{tabular}{|c|c|c|c|}
\hline № & Журнал & $\begin{array}{c}\text { Количество } \\
\text { статей }\end{array}$ & $\begin{array}{c}\text { Доля от общего } \\
\text { количества статей, \% }\end{array}$ \\
\hline 1 & International Journal of Psychophysiology & 51 & 10.6 \\
\hline 2 & Physiology and Behavior & 29 & 6.0 \\
\hline 3 & Personality and Individual Differences & 23 & 4.8 \\
\hline 4 & Journal of Cross-Cultural Psychology & 23 & 4.8 \\
\hline 5 & $\begin{array}{l}\text { AIDS Care: Psychological and Socio-medical } \\
\text { Aspects of AIDS/HIV }\end{array}$ & 14 & 2.9 \\
\hline 6 & Behavior Genetics & 13 & 2.7 \\
\hline 7 & Intelligence & 13 & 2.7 \\
\hline 8 & Learning and Individual Differences & 11 & 2.3 \\
\hline 9 & Frontiers in Psychology & 10 & 2.1 \\
\hline 10 & Frontiers in Human Neuroscience & 9 & 1.9 \\
\hline 11 & Neuropsychologia & 9 & 1.9 \\
\hline 12 & Aggressive Behavior & 8 & 1.7 \\
\hline 13 & Development and Psychopathology & 8 & 1.7 \\
\hline 14 & Journal of Mathematical Psychology & 7 & 1.5 \\
\hline 15 & Behavior Research Methods & 6 & 1.2 \\
\hline 16 & European Psychologist & 6 & 1.2 \\
\hline 17 & $\begin{array}{l}\text { Human Psychopharmacology: Clinical and } \\
\text { Experimental }\end{array}$ & 6 & 1.2 \\
\hline 18 & Journal of Clinical Psychiatry & 6 & 1.2 \\
\hline 19 & Laterality & 6 & 1.2 \\
\hline 21 & Addictive Behaviors & 5 & 1.0 \\
\hline 23 & Brain and Language & 5 & 1.0 \\
\hline 24 & Cognition and Emotion & 5 & 1.0 \\
\hline 25 & European Child and Adolescent Psychiatry & 5 & 1.0 \\
\hline 26 & Journal of Research in Personality & 5 & 1.0 \\
\hline 27 & Neurobiology of Learning and Memory & 5 & 1.0 \\
\hline 28 & Psychophysiology & 5 & 1.0 \\
\hline
\end{tabular}

При этом наиболее быстрый рост количества публикаций отмечается у авторов из Бразилии и Польши. Последние пять лет авторы из этих стран значительно увеличили количество публикаций в ведущих психологических 
Общее количество публикаций (A) и количество публикаций на 1 млн жителей $(\mathrm{B})$ в ведущих международных психологических журналах по годам для нескольких стран. Данные о населении стран (2015 г.) приводятся по «World Development Indicators» (http://data.worldbank.org/)
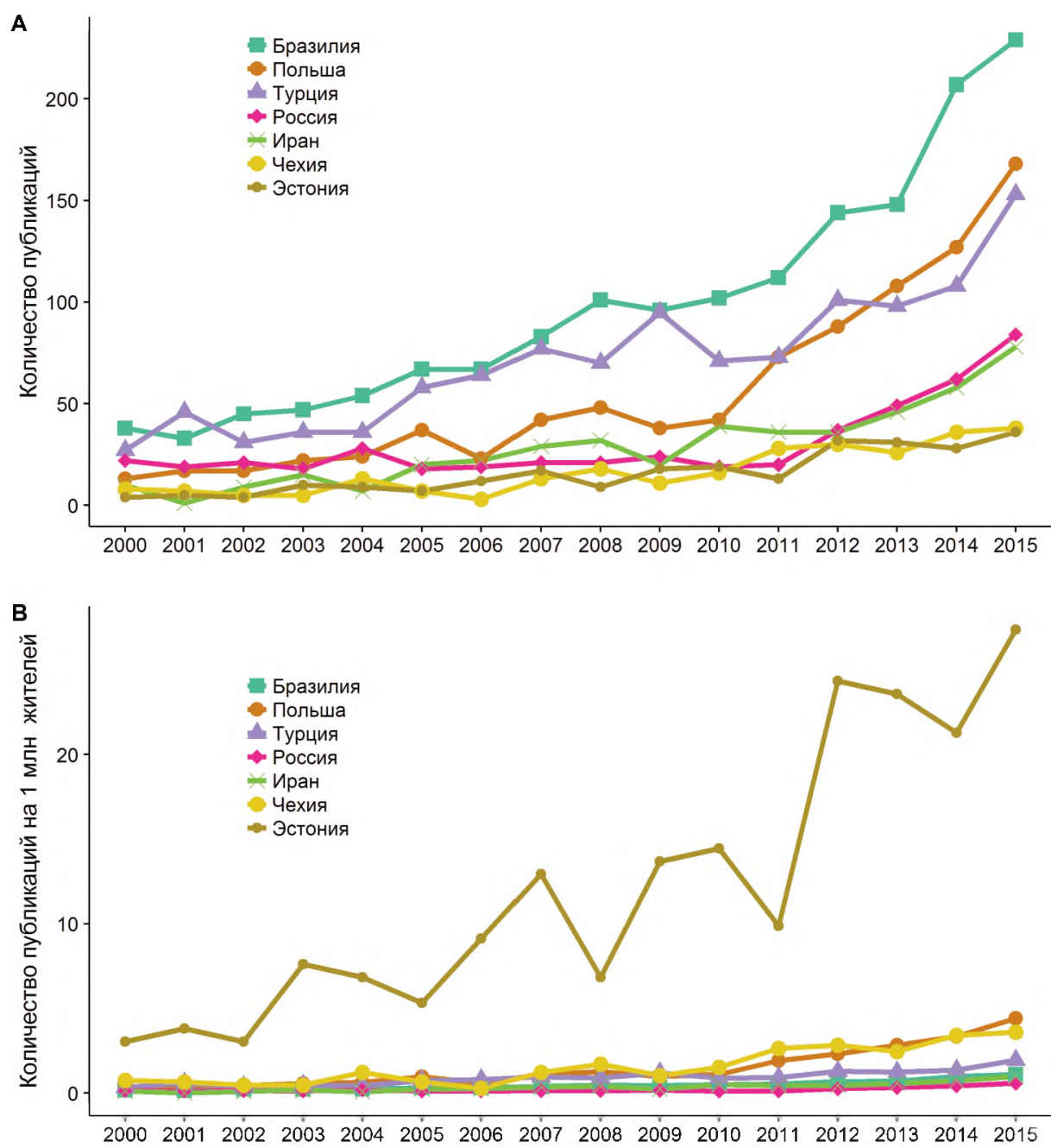

журналах, которое более чем вдвое выше, чем у российских авторов. На рисунке 1 В приводится относительное количество публикаций в этих странах, нормированное на численность их населения. По этому показа- телю абсолютным лидером среди выделенных стран является Эстония, на протяжении всего анализируемого периода имеющая наибольшее количество публикаций на 1 млн жителей в ведущих международных 
психологических журналах, которое в 2015 г. превысило значение 27, следующими по количеству публикаций являются Польша и Чехия. Россия занимает последнее место по данному показателю среди 7 стран и имеет всего 0.58 статей на 1 млн жителей, опубликованных в ведущих международных психологических журналах в 2015 г.

Чтобы понять структуру российских публикаций, были оценены доли разных статей в общем потоке. В таблице 2 представлено распределение статей по тематическим категориям Web of Science. Больше всего статей опубликовано в журналах по экспериментальной психологии, биологической психологии и в междисциплинарных психологических журналах, публикующих статьи разной тематики. Менее всего россий- ские авторы представлены в журналах по математической, прикладной и педагогической психологии. В некоторых категориях после 2011 2012 гг. наблюдается рост количества статей (экспериментальная, биологическая и клиническая психология), в других - количество остается примерно таким же (математическая и прикладная психология), в третьих количество статей сильно варьируется год от года (социальная и педагогическая психология) (см. рисунок 2). На рисунке 3 показано распределение количества статей с разными характеристиками по годам. В последние годы наблюдается рост абсолютного числа трех из четырех типов статей (статьи, написанные кросскультурной коллаборацией, статьи, написанные коллективами сотрудников лабораторий, созданных на

Таблица 2

Распределение статей российских авторов в ведущих международных психологических журналах по тематическим категориям Web of Science

\begin{tabular}{|l|c|c|}
\hline \multicolumn{1}{|c|}{ Категория } & Количество статей & $\begin{array}{c}\text { Доля от общего количества } \\
\text { статей, \% }\end{array}$ \\
\hline Psychology, Experimental & 112 & 23.2 \\
\hline Psychology, Multidisciplinary & 111 & 23.0 \\
\hline Psychology & 104 & 21.6 \\
\hline Psychology, Biological & 92 & 19.1 \\
\hline Psychology, Social & 78 & 16.2 \\
\hline Psychology, Clinical & 58 & 12.0 \\
\hline Psychology, Developmental & 48 & 10.0 \\
\hline Psychology, Educational & 24 & 5.0 \\
\hline Psychology, Applied & 14 & 2.9 \\
\hline Psychology, Mathematical & 13 & 2.7 \\
\hline
\end{tabular}

Примечание. Сумма статей превышает 482 и 100\%, поскольку некоторые журналы относятся к нескольким категориям. 
Количество публикаций по годам для разных категорий. Категории Psychology, Multidisciplinary и Psychology опущены, так как включают статьи по разным отраслям

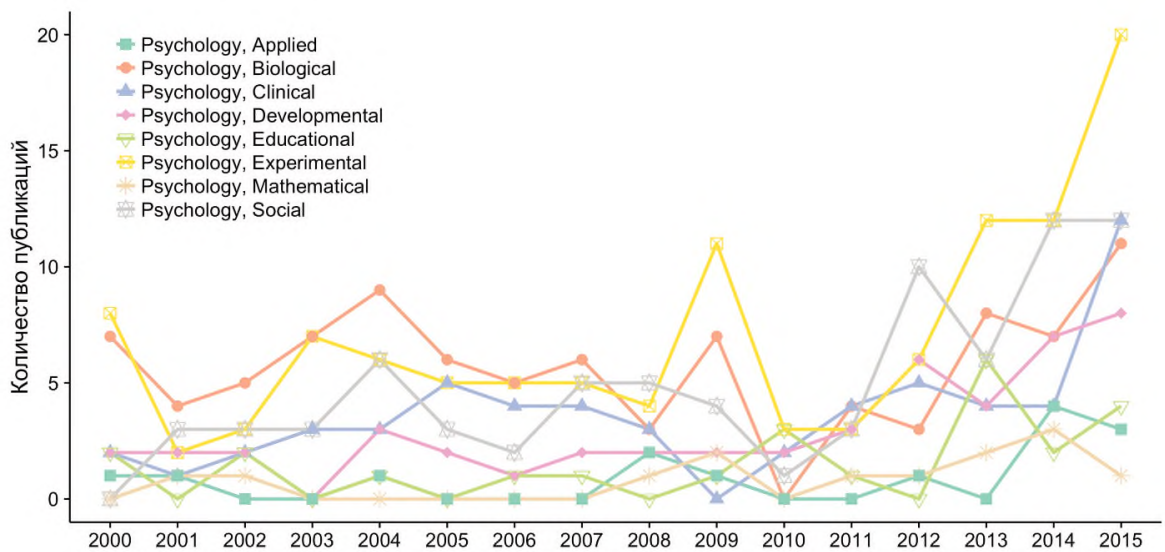

Puсуиок 3

Количество статей с разными характеристиками по годам (А - количество публикаций, В - процент от всех публикаций конкретного года)
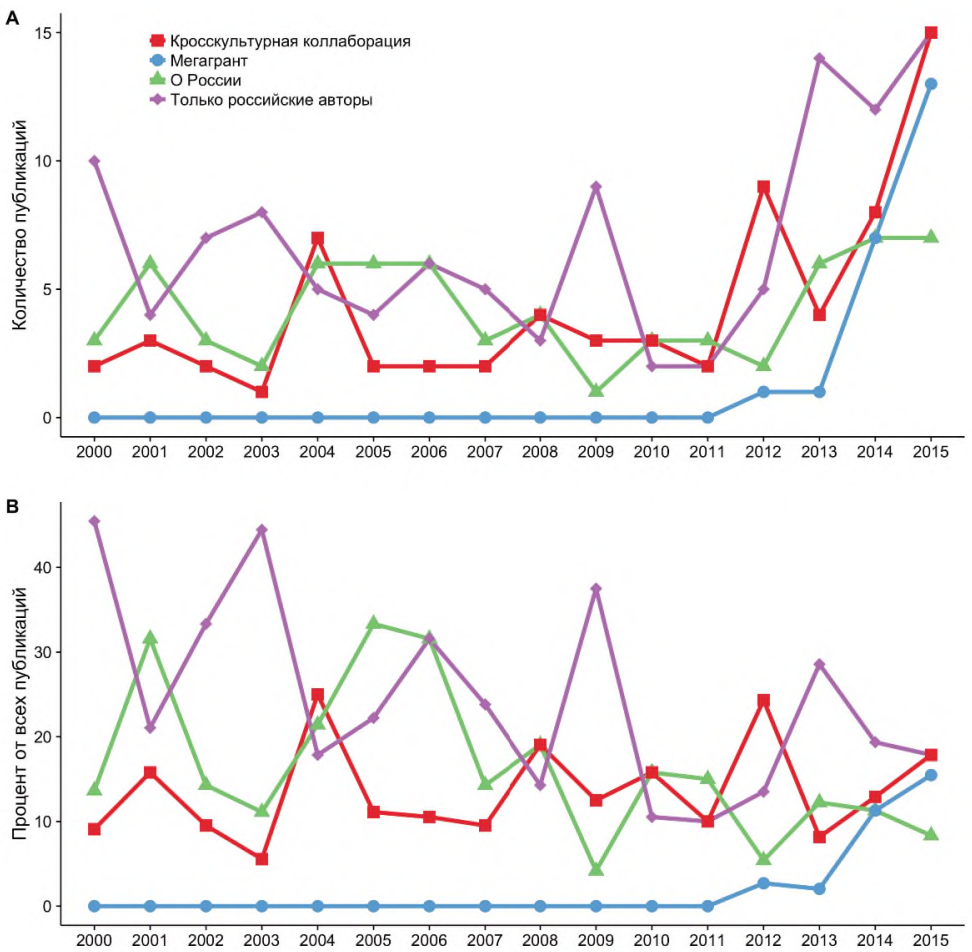
«мегагранты», статьи, написанные только российскими авторами). Однако доля таких статей от общего числа статей, вышедших за год, остается примерно одинаковой (при этом сильно варьируется год от года), за исключением статей, написанных в рамках «мегагрантов». Впервые они появились в 2012 г. и в последние три года их количество растет. В 2014 г. почти каждая десятая статья российских авторов были написана в рамках «мегагрантов», а в 2015 г. уже почти каждая пятая. Такие статьи представлены преимущественно в журналах по психологии развития и в мультидисциплинарных психологических журналах.

Российские авторы анализируемых статей работают как в научноисследовательских институтах, так и в вузах (см. таблицу 3). Почти половина всех статей в ведущих журналах $(40.2 \%)$ написана сотрудниками Российской академии наук (РАН). $\mathrm{Ha}$ данный момент учреждения Российской академии медицинских наук (РАМН) входят в состав Отделения медицинских наук РАН, но, поскольку данные о публикациях собирались и за период, предшествующий реорганизации РАМН,

Таблица 3

Топ-10 организаций, в которых работают российские авторы статей ведущих международных психологических журналов

\begin{tabular}{|c|l|c|c|}
\hline \multicolumn{1}{|c|}{ № } & \multicolumn{1}{|c|}{ Организация } & $\begin{array}{c}\text { Количество } \\
\text { статей }\end{array}$ & $\begin{array}{c}\text { Доля от общего } \\
\text { количества статей, \% }\end{array}$ \\
\hline 1 & Российская академия наук & 194 & 40.2 \\
\hline 2 & $\begin{array}{l}\text { Московский государственный университет } \\
\text { имени М.В. Ломоносова }\end{array}$ & 77 & 16.0 \\
\hline 3 & Российская академия медицинских наук & 57 & 10.6 \\
\hline 4 & $\begin{array}{l}\text { Национальный исследовательский } \\
\text { университет «Высшая школа экономики» }\end{array}$ & 51 & 6.8 \\
\hline 5 & $\begin{array}{l}\text { Санкт-Петербургский государственный } \\
\text { университет }\end{array}$ & 33 & 5.2 \\
\hline 6 & $\begin{array}{l}\text { Московский государственный психолого- } \\
\text { педагогический университет }\end{array}$ & 25 & 4.4 \\
\hline 7 & Томский государственньй университет & 21 & 2.3 \\
\hline 8 & $\begin{array}{l}\text { Новосибирский государственный } \\
\text { университет }\end{array}$ & 11 & 1.7 \\
\hline 9 & Российская академия образования & 7 & 1.5 \\
\hline 10 & $\begin{array}{l}\text { Северный государственный медицинский } \\
\text { университет }\end{array}$ & 7 & \\
\hline
\end{tabular}

Примечание. Сумма статей превышает 482 и 100\%, поскольку сотрудники разных организаций являются авторами одной и той же статьи. 
она выделена в самостоятельную организацию. Среди вузов наибольшее число публикаций в ведущих журналах написано сотрудниками Московского государственного университета имени М.В. Ломоносова, Высшей школы экономики, СанктПетербургского государственного университета.

Чаще всего анализируемые статьи написаны коллективом от двух до шести авторов. Среднее количество авторов - 6.22, медиана - 4. Однако встречаются и статьи, имеющие 15 и более авторов. Как правило, такие статьи описывают результаты исследований больших международных коллабораций, например, в области кросс-культурных исследований. Количество авторов в одной статье может достигать нескольких десятков. Лидером по количеству авторов (91 человек) в нашей выборке является статья, посвященная кросс-культурному исследованию стереотипов о лжецах (Global Deception Res Team, 2006). В целом каждая седьмая российская статья (14.3\%) написана кросс-культурной коллаборацией авторов, использующих в исследовании выборки из разных стран и культур. Ожидаемо, что наибольшее количество таких статей встречается в социальной психологии. Почти каждая пятая российская статья в журналах, относящихся к клинической или прикладной психологии, также написана кросс-культурной коллаборацией (см. таблицу 4). Однако среди статей, написанных большими международными коллаборациями, есть и другие проекты. Например, очередное издание Руководства по созданию и проведению Центра оценки (Rupp et al., 2015).
Наблюдается существенный разброс в авторском составе статей между разными категориями (см. таблицу 4). Наименьшее количество авторов на статью наблюдается в статьях по математической психологии и психологии образования, в обеих категориях максимум авторов на статью не превышает 8 человек. Наибольшее же количество авторов на статью наблюдается в социальной, прикладной и клинической психологии. Наиболее высокий процент статей, написанных одним автором, наблюдается в математической и социальной психологии. Моноавторские статьи вообще не встречаются в прикладной психологии и психологии развития.

Авторский коллектив анализируемых статей чаще всего включает участников из разных стран. Кроме России, среди стран, в которых работают соавторы, наиболее часто встречается СШІА, почти половина всех статей (40.2\%) российских авторов в ведущих журналах написана в соавторстве с американскими учеными. На втором месте - Англия, на третьем - Германия (см. таблицу 5). Лишь 23\% статей написано исключительно российскими авторами. Доля таких статей немного варьируется в разных категориях (см. таблицу 4). Среди статей по биологической психологии она наибольшая (42.4\%), а среди статей по психологии развития, клинической и прикладной психологии она наименьшая $(0,10.5$ и 14.3\% соответственно).

\section{Анализ индивидуальных авторов}

Из всей совокупности авторов 482 анализируемых статей были 
Таблииа 4

Характеристики российских статей в ведущих международных психологических журналах из разных тематических категорий

\begin{tabular}{|c|c|c|c|c|c|c|c|c|c|}
\hline Категория & $\begin{array}{c}\text { Среднее } \\
\text { кол-во } \\
\text { авторов } \\
\text { на статью }\end{array}$ & $\begin{array}{c}\text { Медиана } \\
\text { количества } \\
\text { авторов }\end{array}$ & $\begin{array}{l}\text { Минималь- } \\
\text { ное кол-во } \\
\text { авторов }\end{array}$ & $\begin{array}{c}\text { Максималь- } \\
\text { ное кол-во } \\
\text { авторов }\end{array}$ & $\begin{array}{c}\text { \% статей } \\
\text { с одним } \\
\text { автором }\end{array}$ & $\begin{array}{l}\text { Кол-во } \\
\text { статей о } \\
\text { России }\end{array}$ & $\begin{array}{c}\text { Кол-во } \\
\text { статей } \\
\text { только с } \\
\text { российски- } \\
\text { ми авторами }\end{array}$ & $\begin{array}{c}\text { Кол-во статей } \\
\text { кросс- } \\
\text { культурных } \\
\text { коллабораций }\end{array}$ & $\begin{array}{c}\text { Кол-во } \\
\text { статей в } \\
\text { рамках } \\
\text { «мега- } \\
\text { грантов» }\end{array}$ \\
\hline $\begin{array}{l}\text { Psychology, } \\
\text { Multidisciplinary }\end{array}$ & 5.47 & 4 & 1 & 23 & 9.01 & $20(18.0)$ & $31(27.9)$ & $16(14.4)$ & $6(5.4)$ \\
\hline $\begin{array}{l}\text { Psychology, } \\
\text { Experimental }\end{array}$ & 4.27 & 4 & 1 & 15 & 6.25 & $2(1.8)$ & $36(32.1)$ & $4(3.6)$ & $3(2.7)$ \\
\hline $\begin{array}{l}\text { Psychology, } \\
\text { Social }\end{array}$ & 10.62 & 4 & 1 & 91 & 12.82 & $10(13.2)$ & $13(17.1)$ & $30(39.5)$ & $3(3.9)$ \\
\hline $\begin{array}{l}\text { Psychology, } \\
\text { Biological }\end{array}$ & 4.36 & 4 & 1 & 15 & 6.52 & 0 & $39(42.4)$ & $2(2.2)$ & 0 \\
\hline $\begin{array}{l}\text { Psychology, } \\
\text { Clinical }\end{array}$ & 7.17 & 5.5 & 1 & 40 & 3.45 & $21(36.8)$ & $6(10.5)$ & $11(19.3)$ & $1(1.8)$ \\
\hline $\begin{array}{l}\text { Psychology, } \\
\text { Developmental }\end{array}$ & 6.25 & 6 & 2 & 26 & 0 & $8(17.0)$ & 0 & $6(12.8)$ & $12(25.5)$ \\
\hline $\begin{array}{l}\text { Psychology, } \\
\text { Educational }\end{array}$ & 4.08 & 4 & 1 & 8 & 4.17 & $3(12.5)$ & $4(16.7)$ & $1(4.2)$ & $1(4.2)$ \\
\hline $\begin{array}{l}\text { Psychology, } \\
\text { Mathematical }\end{array}$ & 2.77 & 3 & 1 & 6 & 15.38 & $1(15.4)$ & $4(30.8)$ & 0 & 0 \\
\hline $\begin{array}{l}\text { Psychology, } \\
\text { Applied }\end{array}$ & 9.57 & 3.5 & 2 & 45 & 0 & $5(35.7)$ & $2(14.3)$ & $3(21.4)$ & 0 \\
\hline Все категории & 6.22 & 4 & 1 & 91 & 7.26 & $68(14.1)$ & $111(23.0)$ & $69(14.3)$ & $22(4.6)$ \\
\hline
\end{tabular}

Примечание. Поскольку в категорию Psychology в основном входят журналы, относящиеся и к другим категориям, она не включена в анализ. В скобках указаны проценты. 
Таблица 5

15 наиболее часто встречающихся стран, в которых работают соавторы российских авторов статей в ведущих международных психологических журналах

\begin{tabular}{|c|l|c|c|}
\hline № & \multicolumn{1}{|c|}{ Страна } & Количество общих статей & $\begin{array}{c}\text { Доля от общего количества } \\
\text { статей, \% }\end{array}$ \\
\hline 1 & США & 194 & 40.2 \\
\hline 2 & Великобритания & 77 & 16.0 \\
\hline 3 & Германия & 52 & 10.8 \\
\hline 4 & Нидерланды & 32 & 6.6 \\
\hline 5 & Финляндия & 30 & 6.2 \\
\hline 6 & Канада & 26 & 5.4 \\
\hline 7 & Польша & 26 & 5.4 \\
\hline 8 & Швейцария & 26 & 5.4 \\
\hline 9 & Израиль & 25 & 5.2 \\
\hline 10 & Италия & 24 & 5.0 \\
\hline 11 & Швеция & 24 & 4.6 \\
\hline 12 & Норвегия & 22 & 4.4 \\
\hline 13 & Франция & 21 & 4.4 \\
\hline 14 & Китай & 21 & 3.4 \\
\hline 15 & Япония & 17 & \\
\hline
\end{tabular}

Примеиание. Сумма статей превышает 482 и 100\%, поскольку у одной статьи могут быть авторы не из одной страны.

выделены только российские авторы, у которых хотя бы в одной статье была указана хотя бы одна аффилиация с российской организацией. К сожалению, не во всех анализируемых статьях возможно однозначно сопоставить фамилию автора и его аффилиацию. Систематическая привязка аффилиаций к конкретным авторам в базе Web of Science начинается c 2008 г. В связи с этим для дальнейшего анализа использовались данные только о статьях, вышедших в 2008 г. или позднее. Таких статей оказалось 316. Из данного набора статей были выделены фамилии и имена всех российских авторов. Шесть фамилий имели по два варианта написания. Для них данные по обоим вариантам написания были объединены. Итоговая выборка авторов составила 426 фамилий.

В среднем авторы имеют 1.66 статьи (медиана - 1) из анализируемой выборки. 313 человек, т.е. больше половины (73.5\%), являются авторами только одной статьи. Лишь 19 человек являются авторами пяти и более статей (см. таблицу 6). Восемь из этих 19 авторов на протяжении анализируемого периода имели аффилиации и с российской, 
Таблица 6

Топ-19 российских авторов, имеющих наибольпее количество статей в ведущих международных психологических журналах

\begin{tabular}{|c|c|c|c|c|c|}
\hline Автор & $\mathbf{P}$ & COPP & COPS & ICA & Аффилиации \\
\hline $\begin{array}{l}\text { Grigorenko, } \\
\text { Elena }\end{array}$ & 30 & 5.7 & 91 & 10 & $\begin{array}{l}\text { - Yale University } \\
\text { - Columbia University } \\
\text { - Haskins Labs Inc } \\
\text { - Moscow MV Lomonosov State University } \\
\text { - Moscow State University Psychology \& } \\
\text { Education } \\
\text { - St Petersburg State University }\end{array}$ \\
\hline $\begin{array}{l}\text { Knyazev, } \\
\text { Gennady }\end{array}$ & 18 & 6.3 & 79 & 7 & $\begin{array}{l}\text { - Scientific Research Institute of Physiology } \\
\text { and Basic Medicine, Siberian Branch of the Rus- } \\
\text { sian Academy of Medical Sciences (Novosibirsk) }\end{array}$ \\
\hline $\begin{array}{l}\text { Schwartz, } \\
\text { Shalom }\end{array}$ & 15 & 5.5 & 47 & 21 & $\begin{array}{l}\text { - Hebrew University Jerusalem } \\
\text { - Higher School of Economics }\end{array}$ \\
\hline Kovas, Yulia & 10 & 10.5 & 61 & 10 & $\begin{array}{l}\text { - King's College London } \\
\text { - Goldsmiths University of London } \\
\text { - Tomsk State University } \\
\text { - Russian Academy of Education (Institute of } \\
\text { Psychology) }\end{array}$ \\
\hline $\begin{array}{l}\text { Bocharov, } \\
\text { Andrey }\end{array}$ & 9 & 3.9 & 13 & 2 & $\begin{array}{l}\text { - Scientific Research Institute of Physiology } \\
\text { and Basic Medicine, Siberian Branch of the Rus- } \\
\text { sian Academy of Medical Sciences (Novosibirsk) } \\
\text { - Novosibirsk State University }\end{array}$ \\
\hline $\begin{array}{l}\text { Slobodskaya, } \\
\text { Helena }\end{array}$ & 9 & 3.5 & 21 & 7 & $\begin{array}{l}\text { - Scientific Research Institute of Physiology } \\
\text { and Basic Medicine, Siberian Branch of the Rus- } \\
\text { sian Academy of Medical Sciences (Novosibirsk) } \\
\text { - Novosibirsk State University }\end{array}$ \\
\hline $\begin{array}{l}\text { Davydov, } \\
\text { Dmitry }\end{array}$ & 8 & 4.5 & 22 & 6 & $\begin{array}{l}\text { - Moscow Research Centre of Narcology } \\
\text { - French National Institute of Health and } \\
\text { Medical Research } \\
\text { - Catholic University Louvain } \\
\text { - PK Anokhin Institute of Normal Physiology } \\
\text { - Russian Academy of Medical Sciences, } \\
\text { Institute of General Pathology and } \\
\text { Pathophysiology } \\
\text { - Sholokhov Moscow State University Humanities }\end{array}$ \\
\hline $\begin{array}{l}\text { Boivin, } \\
\text { Michel }\end{array}$ & 7 & 9.2 & 39 & 8 & $\begin{array}{l}\text { - Laval University } \\
\text { - Tomsk State University } \\
\text { - Research Unit Childrens Psychosocial } \\
\text { Maladjustment }\end{array}$ \\
\hline
\end{tabular}


Таблица 6 (окончание)

\begin{tabular}{|c|c|c|c|c|c|}
\hline Автор & $\mathbf{P}$ & COPP & COPS & ICA & Аффилиации \\
\hline $\begin{array}{l}\text { Malykh, } \\
\text { Sergey }\end{array}$ & 7 & 18.8 & 89 & 31 & $\begin{array}{l}\text { - Tomsk State University } \\
\text { - Russian Academy of Education (Institute of } \\
\text { Psychology) }\end{array}$ \\
\hline $\begin{array}{l}\text { Krupitsky, } \\
\text { Evgeny }\end{array}$ & 6 & 8.8 & 34 & 4 & $\begin{array}{l}\text { - First Pavlov State Med University } \\
\text { - Bekhterev Research Psychoneurol Institute }\end{array}$ \\
\hline $\begin{array}{l}\text { Breugelmans, } \\
\text { Seger }\end{array}$ & 5 & 15.6 & 67 & 24 & $\begin{array}{l}\text { - Tilburg University } \\
\text { - Higher School of Economics }\end{array}$ \\
\hline $\begin{array}{l}\text { Dodonov, } \\
\text { Yury }\end{array}$ & 5 & 2 & 1 & 1 & $\begin{array}{l}\text { - Moscow State University Psychology \& } \\
\text { Education }\end{array}$ \\
\hline $\begin{array}{l}\text { Dodonova, } \\
\text { Yulia }\end{array}$ & 5 & 2 & 1 & 1 & $\begin{array}{l}\text { - Moscow State University Psychology \& } \\
\text { Education } \\
\text { - Patrice Lumumba Peoples Friendship } \\
\text { University }\end{array}$ \\
\hline Dragoy, Olga & 5 & 5.2 & 17 & 6 & $\begin{array}{l}\text { - Higher School of Economics } \\
\text { - Moscow Res Institute of Psychiatry } \\
\text { - University Groningen }\end{array}$ \\
\hline $\begin{array}{l}\text { Grigoriev, } \\
\text { Andrei }\end{array}$ & 5 & 3.4 & 8 & 5 & $\begin{array}{l}\text { - Russian Academy Sciences, Institute of } \\
\text { Psychology } \\
\text { - Moscow City University Psychology \& } \\
\text { Education } \\
\text { - Moscow State Regional University } \\
\text { - Russian Academy of Sciences, Institute of } \\
\text { Linguistics }\end{array}$ \\
\hline $\begin{array}{l}\text { Medvedev, } \\
\text { Svyatoslav }\end{array}$ & 5 & 5.8 & 17 & 4 & $\begin{array}{l}\text { - Russian Academy Sciences, NP Bechtereva } \\
\text { Institute Human Brain, St Petersburg }\end{array}$ \\
\hline $\begin{array}{l}\text { Naumova, } \\
\text { Oksana }\end{array}$ & 5 & 6.6 & 19 & 4 & $\begin{array}{l}\text { - Yale University } \\
\text { - Russian Academy Sciences, Vavilov } \\
\text { Institute General Genetics }\end{array}$ \\
\hline Oskina, Irina & 5 & 8.0 & 23 & 2 & $\begin{array}{l}\text { - Russian Academy Sciences, Institute } \\
\text { Cytology \& Genetics, Novosibirsk }\end{array}$ \\
\hline $\begin{array}{l}\text { Savostyanov, } \\
\text { Alexander }\end{array}$ & 5 & 5.0 & 14 & 3 & $\begin{array}{l}\text { - Tomsk State University; } \\
\text { - Scientific Research Institute of Physiology } \\
\text { and Basic Medicine, Siberian Branch of the } \\
\text { Russian Academy of Medical Sciences } \\
\text { (Novosibirsk); } \\
\text { - Novosibirsk State University }\end{array}$ \\
\hline
\end{tabular}

Примечание. В таблице приводятся авторы, имеющие пять и более статей. Р - общее количество статей, СОРР - среднее количество авторов на статью, СОРS - общее количество соавторов в анализируемом временном промежутке, ICA - общее количество стран, с которыми аффилированы авторы статей данного исследователя. 
и с зарубежной организациями. Для пяти из них зарубежный университет является основным местом работы, а с российскими университетами они сотрудничают на условиях совместительства. Среди наиболее продуктивных авторов есть два руководителя лабораторий, созданных на основе «мегагрантов» (Е.Л. Григоренко, основная аффилиация - Йельский университет; Ю. Ковас, основная аффилиация - Голдсмитский колледж Лондонского университета), а также ряд сотрудников этих лабораторий (С.Б. Малых, А.Н. Савостьянов, М. Буавен). Ш. Шварц (Еврейский университет в Иерусалиме) и C. Брейгельманс (Тилбургский университет) параллельно с основной работой сотрудничают с Международной научно-учебной лабораторией социокультурных исследований НИУ ВШЭ. Однако среди авторов с наибольшим количеством статей есть и чисто российские, при этом четверо из них представляют одну организацию - Институт физиологии и фундаментальной медицины (Новосибирск), входивший в структуру Сибирского отделения РАМН.

Чтобы понять, существует ли стабильная группа авторов, постоянно публикующихся в ведущих журналах, или состав авторов меняется от года к году, была проанализирована представленность одних и тех же авторов на разных временных отрезках. Анализируемый период с 2008 по 2015 г. был разделен на четыре двухлетних отрезка. Лишь шестеро авторов систематически публиковали статьи в ведущих журналах на протяжении всего анализируемого периода с 2008 по 2015 г. Чуть больше авторов (от 9 до 29) имеют публи- кации, относящиеся к любым из двух временны́х отрезков. Больше всего авторов (29) имеют статьи, относящиеся к двум последним периодам (с 2012 по 2015 г.). Однако они составляют менее 1\% от 112 авторов, имеющих более одной публикации в анализируемой выборке. Таким образом, существует крайне маленькая группа российских авторов, систематически публикующихся в ведущих международных журналах на протяжении нескольких лет (фамилии этих исследователей приводятся в таблице 7). Однако наблюдается рост таких авторов в последние пять лет.

\section{Заключение}

Целью исследования был анализ российских авторов и их статей, опубликованных в ведуших международных научных журналах. На основе анализа можно сделать несколько выводов.

Во-первых, если до 2011 г. количество российских статей в ведущих международных научных журналах держалось примерно на одном уровне, то в последующие годы наблюдается линейный рост. Однако по сравнению с другими странами, в частности с Бразилией и Польшей, темпы этого роста низкие. Если интенсивный рост числа публикаций указанных стран является следствием активных реформ и увеличения финансирования в сфере образования и науки (Abbott, Schiermeier, 2014; Massarani, 2013), то можно предположить, что устройство российской академической системы и ее финансирование пока далеки от идеальных, по крайней мере, в области 
Список авторов, опубликовавших статьи в двух и более временнб́х отрезках

\begin{tabular}{|c|c|}
\hline Автор & Аффилиация на данный момент \\
\hline \multicolumn{2}{|r|}{ Bce 4 nериода } \\
\hline Bocharov, Andrey & $\begin{array}{l}\text { НИИ физиологии и фундаментальной медицины; } \\
\text { Новосибирский национальный исследовательский } \\
\text { государственный университет }\end{array}$ \\
\hline Davydov, Dmitry & НИИ общей патологии и патофизиологии РАМН \\
\hline Grigorenko, Elena & $\begin{array}{l}\text { Yale University (США); Московский государственный } \\
\text { психолого-педагогический университет }\end{array}$ \\
\hline Knyazev, Gennady & НИИ физиологии и фундаментальной медицины \\
\hline Medvedev, Svyatoslav & Институт мозга человека имени Н.П. Бехтеревой РАН \\
\hline Slobodskaya, Helena & $\begin{array}{l}\text { НИИ физиологии и фундаментальной медицины; } \\
\text { Новосибирский национальный исследовательский } \\
\text { государственный университет }\end{array}$ \\
\hline \multicolumn{2}{|r|}{3 nерuода } \\
\hline Grigoriev, Andrei & Институт психологии РАН \\
\hline Oskina, Irina & Институт цитологии и генетики Сибирского отделения РАН \\
\hline Plyusnina, Irina & Институт цитологии и генетики Сибирского отделения РАН \\
\hline Savostyanov, Alexander & НИИ физиологии и фундаментальной медицины \\
\hline Sysoeva, Olga & $\begin{array}{l}\text { Московский государственный психолого-педагогический } \\
\text { университет (МЭГ-центр) }\end{array}$ \\
\hline \multicolumn{2}{|r|}{2 nериода } \\
\hline Bardenstein, Leonid & $\begin{array}{l}\text { Московский государственный медико-стоматологический } \\
\text { университет имени А.И. Евдокимова }\end{array}$ \\
\hline Blokhina, Elena & $\begin{array}{l}\text { Первый Санкт-Петербургский государственный медицинский } \\
\text { университет имени академика И.П. Павлова }\end{array}$ \\
\hline Butkevich, Irina & Институт физиологии имени И.П. Павлова РАН \\
\hline Butovskaya, Marina & Институт этнологии и антропологии РАН, РГГУ \\
\hline Dragoy, Olga & $\begin{array}{l}\text { Национальный исследовательский университет «Высшая } \\
\text { школа экономики»; Московский НИИ психиатрии Росздрава }\end{array}$ \\
\hline Fedorenko, Olga & $\begin{array}{l}\text { Научно-исследовательский институт психического здоровья } \\
\text { (Томск) }\end{array}$ \\
\hline Gulevich, Rimma & Институт цитологии и генетики Сибирского отделения РАН \\
\hline
\end{tabular}


Таблица 7 (продолжение)

\begin{tabular}{|c|c|}
\hline Автор & Аффилиация на данный момент \\
\hline Ivanova, Svetlana & $\begin{array}{l}\text { Научно-исследовательский институт психического здоровья } \\
\text { (Томск) }\end{array}$ \\
\hline Kharlamova, Anastasiya & Институт цитологии и генетики Сибирского отделения РАН \\
\hline Kireev, Maxim & Институт мозга человека имени Н.П. Бехтеревой РАН \\
\hline Koposov, Roman & University of Tromsø (Норвегия) \\
\hline Korotkov, Alexander & Институт мозга человека имени Н.П. Бехтеревой РАН \\
\hline Kovas, Yulia & $\begin{array}{l}\text { Goldsmiths, University of London (Великобритания); Томский } \\
\text { государственный университет; Психологический институт РАО }\end{array}$ \\
\hline Kropotov, Juri & $\begin{array}{l}\text { Norwegian University of Science and Technology (Норвегия); } \\
\text { Институт мозга человека имени Н.П. Бехтеревой РАН }\end{array}$ \\
\hline Krupitsky, Evgeny & $\begin{array}{l}\text { Первый Санкт-Петербургский государственный медицинский } \\
\text { университет имени академика И.П. Павлова; Санкт- } \\
\text { Петербургский научно-исследовательский } \\
\text { психоневрологический институт имени В.М. Бехтерева }\end{array}$ \\
\hline Lebedeva, Nadezhda & $\begin{array}{l}\text { Национальный исследовательский университет «Высшая } \\
\text { школа экономики» }\end{array}$ \\
\hline Levina, Olga & Региональная общественная организация «Стеллит» \\
\hline Malykh, Sergey & $\begin{array}{l}\text { Психологический институт РАО; Томский государственный } \\
\text { университет }\end{array}$ \\
\hline Mikhailenko, Victor & Институт физиологии имени И.П. Павлова РАН \\
\hline $\begin{array}{l}\text { Muhamedrahimov, } \\
\text { Rifkat }\end{array}$ & Санкт-Петербургский государственный университет \\
\hline Nikitin, N & Институт физиологии имени И.П. Павлова РАН \\
\hline $\begin{array}{l}\text { Petropavlovskaia, } \\
\text { Ekaterina }\end{array}$ & Институт физиологии имени И.П. Павлова РАН \\
\hline Pylkova, Liudmila & НИИ физиологии и фундаментальной медицины \\
\hline Reznikova, Zhanna & $\begin{array}{l}\text { Новосибирский государственный университет; Институт } \\
\text { систематики и экологии животных СО РАН }\end{array}$ \\
\hline Ryabichenko, Tatiana & $\begin{array}{l}\text { Новосибирский государственный медицинский университет; } \\
\text { Научный центр клинической и экспериментальной медицины }\end{array}$ \\
\hline Schmidt, Peter & University of Giessen (Германия) \\
\hline
\end{tabular}


Таблица 7 (окониание)

\begin{tabular}{|c|c|}
\hline Автор & Аффилиация на данный момент \\
\hline Schwartz, Shalom & $\begin{array}{l}\text { The Hebrew University of Jerusalem (Израиль); Национальный } \\
\text { исследовательский университет «Высшая школа экономики» }\end{array}$ \\
\hline Semke, Arkadiy & $\begin{array}{l}\text { Научно-исследовательский институт психического здоровья } \\
\text { (Томск) }\end{array}$ \\
\hline Shepeleva, Darya & Институт цитологии и генетики Сибирского отделения РАН \\
\hline Shestopalova, Lidiya & Институт физиологии имени И.П. Павлова РАН \\
\hline Shikhevich, Svetlana & Институт цитологии и генетики Сибирского отделения РАН \\
\hline Skochilov, Roman & Санкт-Петербургский государственный университет \\
\hline Stepanov, Igor & Институт экспериментальной медицины \\
\hline Tonevitsky, Alexander & $\begin{array}{l}\text { Московский государственный университет имени } \\
\text { М.В. Ломоносова }\end{array}$ \\
\hline Trut, Lyudmila & Институт цитологии и генетики Сибирского отделения РАН \\
\hline Ushakov, Dmitry & Институт психологии РАН \\
\hline Vaitulevich, Svetlana & Институт физиологии имени И.П. Павлова РАН \\
\hline Velichkovsky, Boris & $\begin{array}{l}\text { Technische Universität Dresden (Германия), НИЦ } \\
\text { «Курчатовский институт» }\end{array}$ \\
\hline Vladimirova, Anastasiya & Институт цитологии и генетики Сибирского отделения РАН \\
\hline Welzel, Christian & $\begin{array}{l}\text { Leuphana University (Германия); Национальный } \\
\text { исследовательский университет «Высшая школа экономики» }\end{array}$ \\
\hline
\end{tabular}

психологической науки. Однако недавние инициативы по переходу от небольших и краткосрочных грантов к большим и более долгосрочным («мегагранты» на создание международных лабораторий или гранты Российского научного фонда) отвечают потребностям науки. Оценка эффективности этих инструментов не являлась целью данного исследования, однако заметен рост количества статей в ведущих журналах, написанных сотрудниками лабораторий, созданных на «мегагранты» (в 2015 г. почти каждая пятая российская статья написана сотрудниками этих лабораторий).

Во-вторых, естественно-научный сегмент российской психологической науки и смежных областей биологии лучше представлен в ведущих международных журналах по сравнению с социальным и прикладным сегментами. Больше всего статей опубликова- 
но в ведущих журналах по экспериментальной психологии, биологической психологии. По этим же тематическим областям в последние годы наблюдается рост количества публикаций. Эти результаты могут отражать как более сильный уровень развития в России естественно-научной области психологии и смежных с ней областей, так и их специфику, особенности организации в них исследований. Если когнитивная психология, психофизиология и нейронауки изучают универсальные для всех людей (а иногда и животных) феномены и процессы, то предмет исследования социальной, прикладной, педагогической психологии часто укоренен в культуру, социальный и политический контекст. В связи с этим специалистам, работающим в естественно-научных областях, проще проводить исследования и получать результаты, интересные для международного сообщества ученых. В остальных областях результаты, полученные на российских данных, интересны, прежде всего, в контексте сравнения их с результатами, полученными в других странах и культуpax. Анализ показал, что наибольшее количество статей российских авторов, описывающих кросс-культурные исследования, встречается именно в журналах по социальной, клинической и прикладной психологии. Другими словами, в ведущих журналах по этим областям российские авторы в большой степени представлены именно как поставшики данных о России. Возможно, такие различия частично объясняют разный уровень международной интегрированности российских исследовате- лей, работающих в разных тематических областях.

В-третьих, значительная часть топовых авторов (имеющих наибольшее количество статей) не являются чисто российскими, так как они имеют второе место работы в зарубежной организации. Существенная часть таких исследователей имеет отношение к нескольким международным лабораториям, созданным как в рамках программы «мегагрантов», так и отдельными университетами. Данное обстоятельство трудно однозначно оценить позитивно или негативно. С одной стороны, таких исследователей трудно считать собственно российскими (они могут проводить в России очень мало времени). С другой стороны, для современной науки наличие нескольких мест работы, в том числе в разных странах, не является чем-то необычным и встречается довольно часто, особенно среди наиболее продуктивных исследователей. В ряду топовых авторов есть и исключительно российские, получившие образование и работающие только в России. Четверо из них представляют одну организацию - Институт физиологии и фундаментальной медицины (Новосибирск), входивший ранее в структуру Сибирского отделения РАМН.

В-четвертых, среди авторов крайне мало тех, кто систематически публикует статьи в ведущих международных журналах на протяжении нескольких лет. Лишь у шести из них есть статьи в ведущих журналах на протяжении всего анализируемого периода (20082015). Это означает, что для большинства авторов, попавших в выборку 
исследования, публикация в ведущем международном психологическом журнале - однократное или нерегулярное событие. Частично этот результат можно объяснить тем, что в выборку также попали исследователи, не являюшиеся психологами и работающие в смежных с психологией областях (нейробиология, нейронауки, психиатрия и др.). Одна часть публикаций таких авторов может быть опубликована в психологических журналах, а другая - в журналах смежных областей. Из-за этого в исследуемую выборку статей могла попасть только часть их пуб- ликаций. То же самое могло случиться с авторами, имеющими одновременно российское и зарубежное места работы и указывающими разные аффилиации в разных статьях. Однако учитывая, что исходная выборка журналов, в которых осуществлялся поиск российских статей, была довольно большая (295 журналов), количество российских авторов, регулярно публикующихся в ведущих международных журналах, незначительно. В последние пять лет наблюдается рост авторов, систематически публикующих статьи в ведущих журналах.

\section{Литература}

Писляков, В. В. (2007). Методы оценки научного знания по показателям цитирования. Соииологиеский журнал, 1, 128-140.

Писляков, В. В. (2014). Библиометрические индикаторы в pecypcax Thomson Reuters. В кн. М. А. Акоев (ред.), Руководство по наукометрии: индикаторы развития науки и технологии (с. 75-109). Екатеринбург: Изд-во Уральского университета.

Ссылки на зарубежные источники см. в разделе References после аналоязыиного блока.

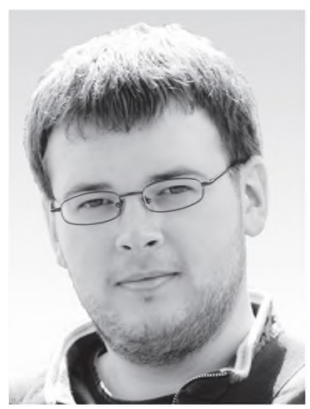

Ловаков Андрей Владимирович - младший научный сотрудник, Институт институциональных исследований, Национальный исследовательский университет «Высшая школа экономики».

Сфера научных интересов: организационная психология, организационная идентификация, организационная приверженность, трудоголизм, увлеченность работой, академическая профессия.

Контакты: lovakov@hse.ru 


\title{
Russian Authors in Leading International Journals in Psychology: A Bibliometric Analysis
}

\author{
A.V. Lovakov \\ National Research University Higher School of Economics, 20 Myasnitskaya Str., Moscow, 101000, \\ Russian Federation
}

\begin{abstract}
The article presents the results of the bibliometric analysis of the Russian articles and their authors, published in the leading international psychological journals (with the highest impactfactor) in the years 2000-2015. The sample consisted of 482 articles of the Russian authors. The analysis showed that in the last years there is a growth of the amount of the Russian publications in the leading international psychological journals. But the rate of this growth in Russia is lower than in other countries with similar elements of academic system. The notable position among the Russian publications of the recent years hold the publications of the scientists of the laboratories, created under the program of "megagrants" (almost each fifth article in 2015). The natural-scientific part of the Russian psychology and the related fields are better represented in the leading international psychological journals than the social and applied parts. In the recent years there is also a noted growth of the amount of publications in this thematic area. Many authors, who have the biggest amount of publications in the leading international psychological journals, are foreigners or have a second place of employment in a foreign organization. Very little amount of authors systematically publish articles in the leading journals from year to year. Only 6 authors systematically published articles in the leading journals in the period 2008-2015. But in the last 5 years there is a growth in the amount of the Russian authors (up to 29 people), who systematically publish articles in the leading journals.
\end{abstract}

Keywords: leading journals, bibliometric analysis, Russian academic society.

\section{References}

Abbott, A., \& Schiermeier, Q. (2014). After the Berlin Wall: Central Europe up close. Nature, 515(7525), 22-25. doi:10.1038/515022a

Abramo, G., D'Angelo, C. A., \& Solazzi, M. (2011). The relationship between scientists' research performance and the degree of internationalization of their research. Scientometrics, 86(3), 629-643. doi:10.1007/s11192-010-0284-7

Global Deception Res Team. (2006). A world of lies.Joumal of Cross-Cultural Psychology, 37(1), 60 74. doi: $10.1177 / 0022022105282295$

Hu, Z., Chen, C., \& Liu, Z. (2014). How are collaboration and productivity correlated at various career stages of scientists? Scientometrics, 101(2), 1553-1564. doi:10.1007/s11192-014-1323-6

Kwiek, M. (2016). The European research elite: a cross-national study of highly productive academics in 11 countries. Higher Education, 71(3), 379-397. doi:10.1007/s10734-015-9910-x 
Lotka, A. J. (1926). The frequency distribution of scientific productivity. Journal of the Washington Academy of Science, 16, 317-323.

Massarani, L. (2013, July 13). Brazil's science investment reaches record high. Nature. doi:10.1038/nature.2013.13495

Mingers, J., \& Leydesdorff, L. (2015). A review of theory and practice in scientometrics. European Journal of Operational Research, 246(1), 1-19. doi:10.1016/j.ejor.2015.04.002

O'Boyle Jr., E., \& Aguinis, H. (2012). The best and the rest: Revisiting the norm of normality of individual performance. Personnel Psychology, 65(1), 79-119. doi:10.1111/j.1744-6570.2011.01239.x

Pislyakov, V. V. (2007). Metody otsenki nauchnogo znaniya po pokazatelyam tsitirovaniya [Methods of assessment of the scientific knowlegde according to the citation index]. Sotsiologicheskii Zhumal, $1,128-140$.

Pislyakov, V. V. (2014). Bibliometricheskie indikatory v resursakh Thomson Reuters [Bibliometric indicators in the resources Thomson Reuters]. In M. A. Akoev (Ed.), Rukovodstvo po naukometrii: indikatory razvitiya nauki i tekhnologii [A handbook in scientometrics: indicators of development of science and technology] (pp. 75-109). Ekaterinburg: Ural University.

Podsakoff, P. M., MacKenzie, S. B., Podsakoff, N. P., \& Bachrach, D. G. (2008). Scholarly influence in the field of management: a bibliometric analysis of the determinants of university and author impact in the management literature in the past quarter century. Joumal of Management, 34(4), 641-720. doi:10.1177/0149206308319533

Ruiz-Castillo, J., \& Costas, R. (2014). The skewness of scientific productivity. Joumal of Informetrics, 8(4), 917-934. doi:10.1016/j.joi.2014.09.006

Rupp, D. E., Hoffman, B. J., Bischof, D., Byham, W., Collins, L., Gibbons, A., ... Thornton, G. (2015). Guidelines and ethical considerations for assessment center operations. Joumal of Management, 41(4), 1244-1273. doi:10.1177/0149206314567780

Andrey V. Lovakov - junior research fellow, Center for Institutional Studies, National Research University Higher School of Economics.

Research area: organizational psychology, organizational identification, organizational commitment, workaholism, work engagement, academic profession.

E-mail: lovakov@hse.ru 